\title{
Jiangella gansuensis gen. nov., sp. nov., a novel actinomycete from a desert soil in north-west China
}

\author{
Lei Song, ${ }^{1,2,3}+$ Wen-Jun Li, ${ }^{2}+$ Qi-Lan Wang, ${ }^{1}$ Guo-Zhong Chen, ${ }^{2}$ \\ Yao-Sheng Zhang ${ }^{1}$ and Li-Hua $\mathrm{Xu}^{2}$ \\ ${ }^{1}$ Northwest Institute of Plateau Biology, CAS, Xining, Qinghai, 810008, People's Republic of \\ China \\ ${ }^{2}$ The Key Laboratory for Microbial Resources of the Ministry of Education, Yunnan Institute of \\ Microbiology, Yunnan University, Kunming, Yunnan, 650091, People's Republic of China \\ ${ }^{3}$ Graduate School of the Chinese Academy of Sciences, Beijing, 100039, People's Republic of \\ China
}

Correspondence

Li-Hua Xu

wjli@ynu.edu.cn or

lihxu@ynu.edu.cn

\begin{abstract}
A novel actinomycete strain, designated $\mathrm{YIM} 002^{\top}$, was isolated from a desert soil sample in Gansu Province, north-west China. This actinomycete isolate formed well-differentiated aerial and substrate mycelia. In the early stages of growth, the substrate mycelia fragmented into short or elongated rods. Chemotaxonomically, it contained LL-2,6-diaminopimelic acid in the cell wall. The cell-wall sugars contained ribose and glucose. Phospholipids present were phosphatidylinositol mannosides, phosphatidylinositol and diphosphatidylglycerol. MK-9 $\left(\mathrm{H}_{4}\right)$ was the predominant menaquinone. The major fatty acids were anteiso $C_{15: 0}(35.92 \%)$, anteiso $C_{17: 0}(15 \cdot 84 \%)$, iso $\mathrm{C}_{15: 0}(10 \cdot 40 \%)$, iso $\mathrm{C}_{16: 0}(7 \cdot 07 \%)$ and $\mathrm{C}_{17: 1} \omega 8 \mathrm{c}(9 \cdot 37 \%)$. The $\mathrm{G}+\mathrm{C}$ content of the DNA was $70 \mathrm{~mol} \%$. Phylogenetic analysis and signature nucleotide data based on 16S rRNA gene sequences showed that strain YIM $002^{\top}$ is distinct from all recognized genera of the family Nocardioidaceae in the suborder Propionibacterineae. On the basis of the phenotypic and genotypic characteristics, it is proposed that isolate $\mathrm{YIM} 002^{\top}$ be classified as a novel species in a new genus, Jiangella gansuensis gen. nov., sp. nov. The type strain is YIM $002^{\top}$ (=DSM

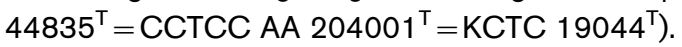

The family Nocardioidaceae was first proposed by Nesterenko et al. (1985) to accommodate two genera, Nocardioides Prauser 1976 and Pimelobacter Suzuki and Komagata 1983. Collins et al. (1989) transferred the Pimelobacter species to the genera Terrabacter and Nocardioides. Currently, the family Nocardioidaceae comprises five genera: Nocardioides (Prauser, 1976), Aeromicrobium (Miller et al., 1991), Kribbella (Park et al., 1999; Sohn et al., 2003), Marmoricola (Urzì et al., 2000) and Actinopolymorpha (Wang et al., 2001). During a project to screen bioactive actinomycete strains from soils, one actinomycete strain, designated YIM $002^{\mathrm{T}}$, was isolated from a desert soil sample collected in Sunan

Published online ahead of print on 29 October 2004 as DOI 10.1099/ ijs.0.63353-0.

†These authors contributed equally to this work.

Abbreviation: LL- $\mathrm{A}_{2} \mathrm{pm}, \mathrm{LL}-2,6-$ diaminopimelic acid.

The GenBank/EMBL/DDBJ accession number for the 16S rRNA gene sequence of strain YIM $002^{\top}$ is AY631071.

Scanning electron micrographs of substrate and aerial mycelia of strain YIM $002^{\top}$ are available as supplementary material in IJSEM Online. county, Gansu Province, north-west China. It contained LL-2,6-diaminopimelic acid (LL-A $\left.\mathrm{A}_{2} \mathrm{pm}\right)$ as the diagnostic amino acid in the peptidoglycan and formed welldifferentiated aerial and substrate mycelia; the substrate mycelia had a tendency to fragment in the early stages of growth. In order to determine the taxonomic and phylogenetic position of this organism, we examined its morphological, physiological and biochemical characteristics and analysed its chemotaxonomic compositions and 16S rRNA gene sequence. The results indicated that strain YIM $002^{\mathrm{T}}$ should be placed in a novel species of a new genus, for which the name Jiangella gansuensis gen. nov., sp. nov. is proposed.

Strain YIM $002^{\mathrm{T}}$ was isolated from the soil sample by using the dilution plating method. The medium used for selective isolation was glycerol-asparagine agar (ISP5 medium; Shirling \& Gottlieb, 1966), which was incubated at $28^{\circ} \mathrm{C}$ for about 2 weeks. Following purification, the organism was maintained on yeast extract-malt extract agar (ISP2 medium; Shirling \& Gottlieb, 1966) at $28^{\circ} \mathrm{C}$.

Strain YIM $002^{\mathrm{T}}$ was grown on ISP2, ISP3, ISP4, ISP5, nutrient agar and Czapek's agar plates at $28^{\circ} \mathrm{C}$. Colour 
determination was performed with colour chips from the ISCC-NBS Colour Charts Standard Samples no. 2106 (Kelly, 1964). Morphological characteristics were examined by light microscopy with a model $\mathrm{BH}-2$ microscope (Olympus) and scanning electron microscopy with a JEOL model JSM5600LV. Morphological features were observed on ISP2 medium at $28^{\circ} \mathrm{C}$. Growth was tested over a range of temperatures $\left(4-45^{\circ} \mathrm{C}\right)$ and $\mathrm{pH}$ values $(6 \cdot 0$ $12 \cdot 0)$. Strain YIM $002^{\mathrm{T}}$ grew well on ISP2 agar but only slowly on the other media tested. Substrate mycelium of YIM $002^{\mathrm{T}}$ fragmented into short or elongated rods; aerial mycelium developed well on ISP2 agar plates (see Supplementary Fig. A in IJSEM Online). The colour of the colonies was white on ISP3 medium and yellow-white on ISP2, ISP4 and ISP5 media, nutrient agar and Czapek's agar plates. No diffusible pigment was produced on any of the media tested. The optimal temperature and $\mathrm{pH}$ for growth were $28^{\circ} \mathrm{C}$ and $7 \cdot 0-8 \cdot 0$, respectively.

Physiological and biochemical characteristics of strain YIM $002^{\mathrm{T}}$ are given in the genus and species descriptions below. All tests were performed at $28{ }^{\circ} \mathrm{C}$ and properties were recorded after 7, 14, 20 and 30 days, except for the nitrate reduction test, which was recorded after 1, 3 and 5 days. Carbon source utilization and sugar fermentation tests were carried out according to the method of Kämpfer et al. (1991).

Procedures for identification of cell-wall amino acids and sugars followed those described by Stanek \& Roberts (1974). Polar lipids were extracted, examined by twodimensional TLC and identified using the procedures of Minnikin et al. (1984). Menaquinones were isolated using the methods of Minnikin et al. (1984) and separated by HPLC (Kroppenstedt, 1982). Cellular fatty acid composition was determined as described by Sasser (1990) using the Microbial Identification System (MIDI, Inc.). Amino acids in the peptidoglycan layer of strain YIM $002^{\mathrm{T}}$ were LL- $\mathrm{A}_{2} \mathrm{pm}$, alanine, glycine and glutamic acid, indicating a type I wall chemotype according to the classification of Lechevalier \& Lechevalier (1970). Cell-wall sugars were glucose and ribose. The predominant menaquinone was MK-9 $\left(\mathrm{H}_{4}\right)$. Phospholipids of strain YIM $002^{\mathrm{T}}$ present were phosphatidylinositol mannosides, phosphatidylinositol and diphosphatidylglycerol. The cellular fatty acid composition of strain YIM $002^{\mathrm{T}}$ is given in the genus and species descriptions.
Chromosomal DNA from strain YIM $002^{\mathrm{T}}$ was prepared following the method of Marmur (1961). The G+C content of the DNA was determined using the thermal denaturation method of Marmur \& Doty (1962); a value of $70 \mathrm{~mol} \%$ was measured.

Amplification of the 16S rRNA gene sequence was performed as described by Cui et al. (2001). Database searching was carried out using the BLAST program. The 16S rRNA gene sequence of strain YIM $002^{\mathrm{T}}$ and previously published sequences of reference actinomycetes were aligned using the CLUSTAL X program (Thompson et al., 1997). A phylogenetic tree was constructed using the neighbour-joining method of Saitou \& Nei (1987) from $K_{\text {nuc }}$ values (Kimura, $1980,1983)$. The reliability of the phylogenetic tree was evaluated using the bootstrap resampling method of Felsenstein (1985) with 1000 replicates.

The almost complete 16S rRNA gene sequence (1497 nt) of strain YIM $002^{\mathrm{T}}$ was obtained (Escherichia coli numbering 29-1542), and BLAST search comparisons were made against the GenBank/EMBL/DDBJ databases. A sequence of $1466 \mathrm{nt}$ was compared after elimination of all sites for which nucleotides were not determined in any sequences. The phylogenetic tree shown in Fig. 1 includes sequences of representative members of the family Nocardioidaceae.

Phylogenetic analysis of the 16S rRNA gene sequence revealed that the isolate fell within the cluster of the family Nocardioidaceae and represented a line of descent distinct from recognized actinomycetes of this family (Fig. 1). Strain YIM $002^{\mathrm{T}}$ formed a monophyletic clade with Actinopolymorpha singaporensis at a low nucleotide sequence similarity $(92 \cdot 3 \%)$. The relationship was confirmed in all three treemaking analyses [least-squares (Fitch \& Margoliash, 1967) and maximum-likelihood (Felsenstein, 1981) (data not shown) as well as neighbour-joining (Fig. 1)] and by the high bootstrap value $(>80 \%)$, based on the neighbourjoining algorithm. The next closest neighbours were Kribbella species, sharing only $91 \cdot 6-92 \cdot 3 \% \quad 16 \mathrm{~S}$ rRNA gene sequence similarities. Strain YIM $002^{\mathrm{T}}$ had no more than $92 \%$ sequence similarity to all other taxa within the family Nocardioidaceae.

Additionally, there are significant differences in morphology and chemotaxonomic characteristics between strain YIM $002^{\mathrm{T}}$ and related genera of the family Nocardioidaceae

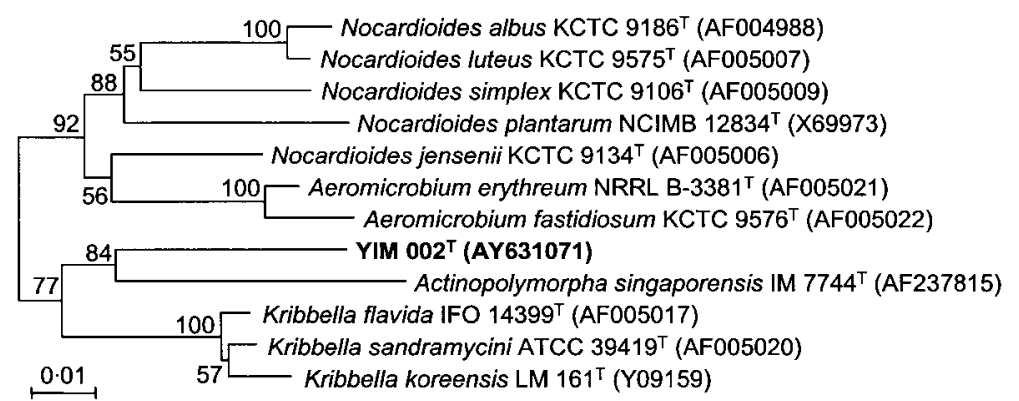

Fig. 1. A neighbour-joining phylogenetic tree of representatives from all recognized genera within the family Nocardioidaceae. Numbers at nodes are bootstrap percentages based on 1000 resamplings. Streptosporangium roseum DSM 43021 ${ }^{\top}$ (X89947) was used as outgroup (not shown). Bar, $1 \%$ sequence divergence. 
Table 1. Differential characteristics of Jiangella gansuensis gen. nov., sp. nov. YIM $002^{\top}$ and related taxa in the family Nocardioidaceae

Data for reference taxa were taken from Prauser (1976), O’Donnell et al. (1982), Collins et al. (1989), Miller et al. (1991), Urzì et al. (2000); Park et al. (1999), Wang et al. (2001) and Sohn et al. (2003). ND, Not determined.

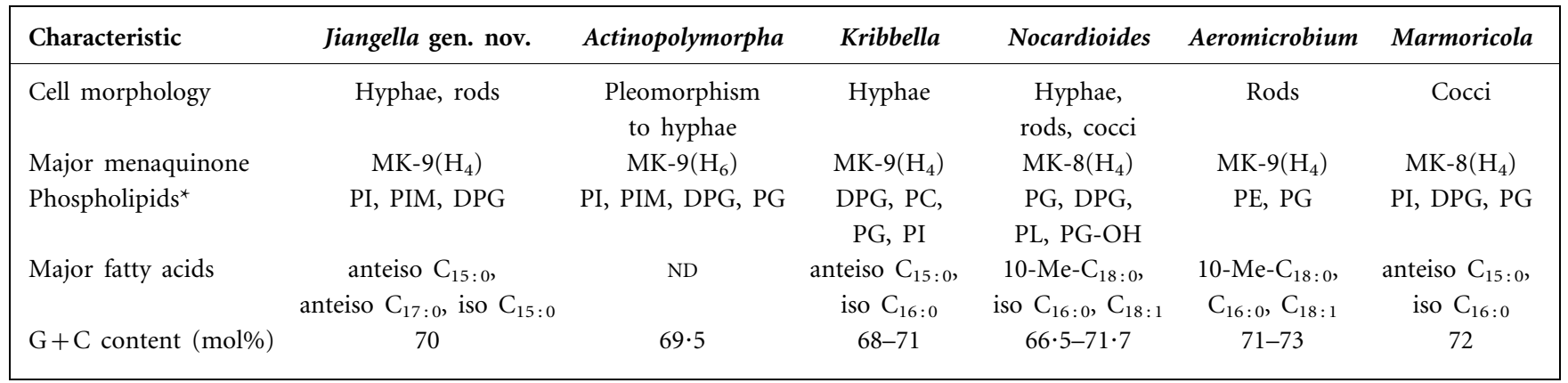

${ }^{\star}$ DPG, Diphosphatidylglycerol; GL, unknown glycolipid(s); PC, phosphatidylcholine; PE, phosphatidylethanolamine; PG, phosphatidylglycerol; PG-OH, phosphatidylglycerol containing 2-hydroxy fatty acids; PI, phosphatidylinositol; PIM, phosphatidylinositol mannosides; PL, unknown phospholipid(s).

(Table 1). We also compared the nucleotide signatures of strain YIM $002^{\mathrm{T}}$ against those specific to the family Nocardioidaceae (Stackebrandt et al., 1997). The results indicated the presence of most of the specific nucleotide signatures in the sequence of strain YIM $002^{\mathrm{T}}$, except for variations at some positions (see under the genus description below).

On the basis of phenotypic and genotypic data, strain YIM $002^{\mathrm{T}}$ is distinguishable from all recognized genera of the family Nocardioidaceae. We consider that the polyphasic evidence presented here is sufficient to propose the classification of strain YIM $002^{\mathrm{T}}$ within a new genus, Jiangella gen. nov., as Jiangella gansuensis sp. nov.

\section{Description of Jiangella gen. nov.}

Jiangella [Ji.ang.el'la. N.L. fem. dim. n. Jiangella after ChengLin Jiang (1942-), a Chinese microbiologist, in recognition of his work on actinomycete taxonomy].

Strictly aerobic and Gram-positive. Substrate mycelium fragments into short or elongated rods in the early stages of growth. Aerial mycelium differentiates well and no spores are formed. Grow very well on ISP2 medium. Cell wall contains LL- $\mathrm{A}_{2} \mathrm{pm}$ as the diamino acid in the peptidoglycan. MK-9 $\left(\mathrm{H}_{4}\right)$ is the predominant menaquinone; cell-wall sugars are glucose and ribose. Phosphatidylinositol mannosides, phosphatidylinositol and diphosphatidylglycerol are present. Major cellular fatty acids are anteiso $C_{15: 0}$, anteiso $\mathrm{C}_{17: 0}$, iso $\mathrm{C}_{15: 0}$, iso $\mathrm{C}_{16: 0}$ and $\mathrm{C}_{17: 1} \omega 8 c$. DNA G $+\mathrm{C}$ content is $70 \mathrm{~mol} \%$. Phylogenetically, the genus is placed in the family Nocardioidaceae. All family-specific nucleotide signatures (Stackebrandt et al., 1997) are present except for a $C: G$ pair at nucleotide positions $370: 391$ instead of $G: C$, a $C: G$ pair at positions $602: 636$ instead of $G: U$ and a $U: U$ pair at positions $658: 748$ instead of $U$ : A. The type species is Jiangella gansuensis.

\section{Description of Jiangella gansuensis sp. nov.}

Jiangella gansuensis (gan.su.en'sis. N.L. fem. adj. gansuensis pertaining to Gansu, a province of north-west China from where the type strain was isolated).

Morphological, chemotaxonomic and general characteristics are as given above for the genus. Colonies are white on ISP3 and yellow-white on ISP2, ISP4 and ISP5 media and nutrient and Czapek's agar plates. No diffusible pigment is produced on these agar plates. Optimal temperature and $\mathrm{pH}$ for growth are $28^{\circ} \mathrm{C}$ and $7 \cdot 0-8 \cdot 0$, respectively. Utilizes glucose, fructose, xylose, rhamnose, mannitol, sucrose, inositol, galactose, mannose, mannitol, arabinose, xylitol, melibiose, maltose, lactose, raffinose, cellobiose, dextrin and glycerol as sole carbon sources, but not ribose. Positive for gelatin hydrolysis, urease, milk coagulation and peptonization, but negative for cellulose hydrolysis, production of $\mathrm{H}_{2} \mathrm{~S}$, starch hydrolysis and nitrate reduction. Fatty acids present are anteiso $\mathrm{C}_{15: 0}(35 \cdot 92 \%)$, anteiso $\mathrm{C}_{17: 0}(15 \cdot 84 \%)$, iso $\mathrm{C}_{15: 0}(10 \cdot 40 \%), \mathrm{C}_{17: 1} \omega 8 c(9 \cdot 37 \%)$, iso $\mathrm{C}_{16: 0}(7 \cdot 07 \%), \mathrm{C}_{17: 0}(3 \cdot 39 \%)$, iso $\mathrm{C}_{17: 0}(3 \cdot 09 \%)$, iso G-C $\mathrm{C}_{16: 1}(2 \cdot 90 \%)$, anteiso $\mathrm{A} \mathrm{C}_{17: 1}(2 \cdot 86 \%), \mathrm{C}_{15: 0} 2-\mathrm{OH}$ $(2 \cdot 28 \%)$, iso $\mathrm{C}_{14: 0} 2-\mathrm{OH}(2 \cdot 23 \%)$, anteiso $\mathrm{A}_{15: 1}$ $(1 \cdot 31 \%), \mathrm{C}_{18: 1} \omega 9 c(1 \cdot 24 \%)$, iso $\mathrm{C}_{17: 1} \omega 9 c(1 \cdot 05 \%)$ and $\mathrm{C}_{15: 0}(1 \cdot 05 \%)$. DNA G $+\mathrm{C}$ content is $70 \mathrm{~mol} \%$.

The type strain, YIM $002^{\mathrm{T}}\left(=\mathrm{DSM} 44835^{\mathrm{T}}=\right.$ CCTCC AA $204001^{\mathrm{T}}=$ KCTC $19044^{\mathrm{T}}$ ), was isolated from a desert soil sample from Gansu Province, China.

\section{Acknowledgements}

We are grateful to Professor Zhi-Heng Liu and Meng-Liang Wen for technical support. This research was supported by the National Basic Research Program of China (project no. 2004CB719601), National Natural Science Foundation of China (project no. 30270004), Yunnan Provincial Natural Science Foundation (project no. 2004C0002Q), 
Yunnan Education Commission Foundation (project no. 02QJ077), Knowledge Innovation Program of CAS (project no. Kzcx1-09-01), Key Research Project of NWIPB of Knowledge Innovation Program, CAS (project no. cjc 020144) and Director Foundation of NWIPB (project no. 110210116).

\section{References}

Collins, M. D., Dorsch, M. \& Stackebrandt, E. (1989). Transfer of Pimelobacter tumescens to Terrabacter gen. nov. as Terrabacter tumescens comb. nov. and of Pimelobacter jensenii to Nocardioides as Nocardioides jensenii comb. nov. Int J Syst Bacteriol 39, 1-6.

Cui, X. L., Mao, P. H., Tseng, M., Li, W. J., Zhang, L. P., Xu, L. H. \& Jiang, C. L. (2001). Streptomonospora salina gen. nov., a new member of the family Nocardiopsaceae. Int J Syst Evol Microbiol 51, 357-363.

Felsenstein, J. (1981). Evolutionary trees from DNA sequences: a maximum likelihood approach. J Mol Evol 17, 368-376.

Felsenstein, J. (1985). Confidence limits on phylogenies: an approach using the bootstrap. Evolution 39, 783-791.

Fitch, W. M. \& Margoliash, E. (1967). Construction of phylogenetic trees: a method based on mutation distances as estimated from cytochrome $c$ sequences is of general applicability. Science 155, 279-284.

Kämpfer, P., Steiof, M. \& Dott, W. (1991). Microbiological characterization of a fuel oil contaminated site including numerical identification of heterotrophic water and soil bacteria. Microb Ecol 21, 227-251.

Kelly, K. L. (1964). Inter-Society Color Council - National Bureau of Standards Color-Name Charts Illustrated with Centroid Colors. Washington, DC: US Government Printing Office.

Kimura, M. (1980). A simple method for estimating evolutionary rates of base substitutions through comparative studies of nucleotide sequences. J Mol Evol 16, 111-120.

Kimura, M. (1983). The Neutral Theory of Molecular Evolution. Cambridge: Cambridge University Press.

Kroppenstedt, R. M. (1982). Separation of bacterial menaquinones by HPLC using reverse phase (RP 18) and a silver loaded ion exchanger as stationary phases. J Liq Chromatogr 5, 2359-2387.

Lechevalier, M. P. \& Lechevalier, H. A. (1970). Chemical composition as a criterion in the classification of aerobic actinomycetes. Int J Syst Bacteriol 20, 435-443.

Marmur, J. (1961). A procedure for the isolation of deoxyribonucleic acid from microorganisms. J Mol Biol 3, 208-218.

Marmur, J. \& Doty, P. (1962). Determination of the base composition of deoxyribonucleic acid from its thermal denaturation temperature. J Mol Biol 5, 109-118.

Miller, E. S., Woese, C. R. \& Brenner, S. (1991). Description of the erythromycin-producing bacterium Arthrobacter sp. strain NRRL B3381 as Aeromicrobium erythreum gen. nov., sp. nov. Int J Syst Bacteriol 41, 363-368.
Minnikin, D. E. O'Donnell A. G., Goodfellow, M., Alderson, G., Athalye, M., Schaal, A. \& Parlett, J. H. (1984). An integrated procedure for the extraction of isoprenoid quinines and polar lipids. J Microbiol Methods 2, 233-241.

Nesterenko, O. A., Kvasnikov, E. I. \& Nogina, T. M. (1985). Nocardioidaceae fam. nov., a new family of the order Actinomycetales Buchanan 1917. Mikrobiol Zh 47, 3-12.

O’Donnell, A. G., Goodfellow, M. \& Minnikin, D. E. (1982). Lipids in the classification of Nocardioides: reclassification of Arthrobacter simplex (Jensen) Lochhead in the genus Nocardioides (Prauser) emend. O'Donnell et al. as Nocardioides simplex comb. nov. Arch Microbiol 133, 323-329.

Park, Y.-H., Yoon, J.-H., Shin, Y. K., Suzuki, K., Kudo, T., Seino, A., Kim, H.-J., Lee, J.-S. \& Lee, S. T. (1999). Classification of 'Nocardioides fulvus' IFO 14399 and Nocardioides sp. ATCC 39419 in Kribbella gen. nov., as Kribbella flavida sp. nov. and Kribbella sandramycini sp. nov. Int J Syst Bacteriol 49, 743-752.

Prauser, H. (1976). Nocardioides, a new genus of the order Actinomycetales. Int J Syst Bacteriol 26, 58-65.

Saitou, N. \& Nei, M. (1987). The neighbor-joining method: a new method for reconstructing phylogenetic trees. Mol Biol Evol 4, 406-425.

Sasser, M. (1990). Identification of bacteria by gas chromatography of cellular fatty acids. USFCC Newsl 20, 16.

Shirling, E. B. \& Gottlieb, D. (1966). Methods for characterization of Streptomyces species. Int J Syst Bacteriol 16, 313-340.

Sohn, K., Hong, S. G., Bae, K. S. \& Chun, J. (2003). Transfer of Hongia koreensis Lee et al. 2000 to the genus Kribbella Park et al. 1999 as Kribbella koreensis comb. nov. Int J Syst Evol Microbiol 53, 1005-1007.

Stackebrandt, E., Rainey, F. A. \& Ward-Rainey, N. L. (1997). Proposal for a new hierarchic classification system, Actinobacteria classis nov. Int J Syst Bacteriol 47, 479-491.

Stanek, J. L. \& Roberts, G. D. (1974). Simplified approach to identification of aerobic actinomycetes by thin-layer chromatography. Appl Microbiol 28, 226-231.

Suzuki, K. \& Komagata, K. (1983). Pimelobacter gen. nov., a new genus of coryneform bacteria with LL-diaminopimelic acid in the cell wall. J Gen Appl Microbiol 29, 59-71.

Thompson, J. D., Gibson, T. J., Plewniak, F., Jeanmougin, F. \& Higgins, D. G. (1997). The CLUSTAL_X windows interface: flexible strategies for multiple sequence alignment aided by quality analysis tools. Nucleic Acids Res 25, 4876-4882.

Urzi, C., Salamone, P., Schumann, P. \& Stackebrandt, E. (2000). Marmoricola aurantiacus gen. nov., sp. nov., a coccoid member of the family Nocardioidaceae isolated from a marble statue. Int J Syst Evol Microbiol 50, 529-536.

Wang, Y. M., Zhang, Z. S., Xu, X. L., Ruan, J. S. \& Wang, Y. (2001). Actinopolymorpha singaporensis gen. nov., sp. nov., a novel actinomycete from the tropical rainforest of Singapore. Int J Syst Evol Microbiol 51, 467-473. 